\title{
Editorial
}

\section{Ophthalmic Research EVICR.net Section - Opening Words}

I have the great pleasure to open a new section in the journal Ophthalmic Research with the main objective of promoting multinational clinical research in ophthalmology, informing regularly on activities of EVICR.net - European Vision Institute Clinical Research Network. EVICR.net is a network of European ophthalmological clinical research sites, dedicated to perform clinical research in ophthalmology with the highest standards of quality, which has grown in the last 3 years. Nine studies are now in progress within EVICR.net, of which 7 are investigator-driven clinical trials.

We all realise that it is crucial to have more investigator-driven clinical trials in order to promote more clinical research in ophthalmology.

It is our intention to have one article each year with information on EVICR. net general activities and one or two others originating from different EVICR. net scientific sections reporting on results achieved by EVICR.net studies or drawing attention to the need for and opportunity of more clinical trials in a specific scientific area.

EVICR.net appreciates to have the opportunity to inform clinical eye researchers of its activities and is looking forward to contributing to the development of clinical trial research in ophthalmology in Europe.

Cecília Martinho 